\title{
2020 Reviewer Acknowledgment
}

\section{Editorial Office of Aging Pathobiology and Therapeutics}

Over the year, many reviewers made outstanding contributions to the peer review process of APT. They demonstrated professional effort and enthusiasm in their reviews and provided comments that genuinely help the authors to enhance their work and improve the quality of APT. The editorial office would like to express our sincere gratitude to the following reviewers for their generous contribution in 2020:

\section{Abbas Salihi}

Department of Biology, College of Science, Salahaddin University-Erbil, Kurdistan Region, Iraq.

\section{Amira Guirguis}

Swansea University Medical School, Institute of Life Sciences, Swansea University, Singleton Park, Swansea, UK.

\section{Ana Dekanic}

Laboratory for Cell Biology and Signalling, Division of Molecular Biology, Ruđer Bošković Institute, Bijenička 54, 10000 Zagreb, Croatia.

\section{Apostolos Papachristos}

Laboratory of Pharmacokinetics, Department of Pharmacy, School of Health Sciences, University of Patras, Patra, Greece.

\section{Christina Sigurdson}

Departments of Pathology and Medicine, University of California, San Diego, La Jolla, CA, USA.

\section{Fang Chen}

Key Laboratory of Human Functional Genomics of Jiangsu Province, Nanjing Medical University, Nanjing, China.

\section{Fernando Faunes}

Center for Aging and Regeneration, Millennium Nucleus in Regenerative Biology, faculty of Biological Sciences, P. Universidad Católica de Chile, Alameda 340, Santiago, Chile.

\section{Hossein Tabatabaeian}

Department of Cell and Molecular Biology and Microbiology, Faculty of Biological Science and Technology, University of Isfahan, Isfahan, Iran.

\section{Hualin Fu}

National Center for Translational Medicine, Shanghai Jiao Tong University, 800 Dongchuan Road, Shanghai 200240, China. 


\section{Irene Torres-Sánchez}

Department of Physical Therapy, Faculty of Health Sciences, University of Granada, Av De la Ilustración, 60-18016 Granada, Spain.

\section{José Luis Aceves}

Department of Cardiothoracic Surgery, National Medical Center, Institute of Security and Social Services of State Workers, Mexico City, Mexico.

\section{Junfeng Sun}

Department of Gastrointestinal Surgery, The First Affiliated Hospital of Zhengzhou University, Zhengzhou, China.

\section{Junko Oshima}

Department of Pathology, University of Washington, Seattle, WA, USA.

\section{Kaoru Tominaga}

Department of Biochemistry, Jichi Medical University, Tochigi, Japan.

\section{Ketan Vagholkar}

Department of Surgery, Dr. D. Y. Patil Medical College, Navi Mumbai, India.

\section{Lin Shen}

Department of GI Oncology, Laboratory of Carcinogenesis and Translational Research of the Ministry of Education, Peking University School of Oncology, Beijing Cancer Hospital \& Institute, Beijing, China.

\section{Meer M. Chisthi}

Department of General Surgery, Government Medical College, Trivandrum, Kerala, 695011, India.

\section{Randy Strong}

NIA Aging Interventions Testing Center and Nathan Shock Center of Excellence in the Biology of Aging, Department of Pharmacology, Barshop Institute on Aging, University of Texas Health Sciences Center at San Antonio, San Antonio, TX, USA.

\section{Ruifeng Zhao}

Department of Infertility, Henan Province Hospital, Zhengzhou, China.

\section{Wagih Mommtaz Ghannam}

Department of General Surgery, Mansoura Faculty of Medicine, Mansoura, Egypt.

\section{Wei Kang}

Department of Anatomical and Cellular Pathology, State Key Laboratory of Oncology in South China, Prince of Wales Hospital, The Chinese University of Hong Kong, Hong Kong, China.

\section{Yan Dou}

Research Scientist, Department of Comparative Medicine, University of Washington, WA, USA. 